\section{AN APPARATUS FOR THE MEASUREMENT OF SMALL QUANTITIES OF FLUID. ${ }^{1}$}

By J. W. TREVAN, M.B., B.S. LoND., WELLCOME PHYSIOLOGICAL RESEARCH LABORATORIES.

THIs apparatus for measuring rolumes of fluid from $0.5 \mathrm{c.cm}$. to $0.005 \mathrm{c.cm}$, with an accuracy of 1 per cent., was designed to measure $0.02 \mathrm{c.cm}$. of diphtheria toxin into capillary tubes for the performance of the Schick test, but can be used for any titration which involves the making of high dilutions-e.g., the Wassermann or other serological reactions.

It consists of a good 1 c.cm. syringe (all-glass "tuberculin" or record) and an engineering micrometer head, clamped in line by brass clamps to a $\frac{1}{2}$ inch steel rod. The micrometer head is graduated in one-hundredths of a millimetre; its motion pushes the piston of the syringe, and the fluid to be measured is delivered through a steel (preferably rustless) needle under the surface of the diluent (to avoid drop errors). The knob on the piston is either ground plane or drawn out to a rounded point. The instrument can be calibrated roughly by measuring the distance between the marks on the syringe and calculating the volume corresponding to $1 / 100 \mathrm{~mm}$. $(=1 / 50$ of a turn of the head of the micrometer), or by weighing mercury delivered.

The piston must be thoroughly wetted with the fluid to be used before setting up. The usual micrometer found in most laboratories can be used if a copper trough is made and arranged so that the anvil of the micrometer fits into the hollow of the trough, one end of which clips on to the knob of the piston, and the other is closed by a flat plate on which the plunger of the micrometer works.

Calibration of successive turns gave the following results :- -

1. By weighing mercury: 34 readings, 1 turn of the head of the micrometer $=0.1276 \pm 0.0094 \mathrm{~g}$. mercury $=$ less than 1 per cent. Corresponds to 0.0190 c.cm. per mm. Direct measurement gave 0.0192 c.cm. per $\mathrm{mm}$.

2. By ejecting 50 per cent. calcium chloride under the surface of water in a beaker and titrating with $\mathrm{N} / 50 \mathrm{AgNO}_{3}$ and chromate: (a) All-glass 1 c.cm. syringe. 4 turns, 8 readings gave $10.91 \mathrm{c.cm}$. $\mathrm{Ag} \mathrm{NO}_{3}$ average, extreme error $0.05 \mathrm{c.cm} . \mathrm{AgNO}_{3}=$ less than 1 per cent. (b) Record $0.3 \mathrm{c.cm}$. syringe gave $6.317 \mathrm{c.cm}$. $\mathrm{AgNO}$ for 4 turns (about $0.02 \mathrm{c.cm}$.) extreme error $0.055 \mathrm{c.cm} . \mathrm{AgNO}_{3}=$ less than 1 per cent.

1 Shown at the Pathological Section of the Royal Society of Modicine, Feb. 21 st, 1922 .
3. By measuring the number of turns to eject a standard drop of fluid : (a) All-glass syringe, 34 readings : 1 drop $=1.0263 \mathrm{~mm}$., extreme error $=0.0075 \mathrm{~mm}$ $=0.76$ per cent. on a volume of $0.0190 \mathrm{c.cm} .(b)$ Record syringe: using mercury as a dropping fluid, volume of 1 drop $0.0001 \mathrm{c.cm} ., 10$ drops of mercury $(0.001 \mathrm{c.cm})=$.0.099 to $0.109 \mathrm{~mm}$. movement of the micrometer head; error less than 5 per cent. The chance of the mercury drop varying in volume is so great owing to the ease with which it becomes contaminated that the error of the method of calibration is probably greater than the error of the measure. ment by the syringe.

\section{RUPTURE OF CAESAREAN SECTION SCAR} IN SUBSEQUENT PREGNANCY OR LABOUR.*

BY W. R. MACKENZIE, L.R.C.P. \& S. EdIN., SURGEON, SAMARITAN HOSPITAL FOR WOMEN, BELFAST.

IN former days contracted pelvis was the only indication for Cæsarean section and repeated operation the only method of delivery in subsequent pregnancies, when scars were seldom overstrained by labour. Nowadays the scope of the operation is much wider, and the accepted indications include such complications of pregnancy as tumours obstructing labour, eclampsia, prolapsed cord, severe accidental hæmorrhage, rigidity of the cervix and vagina. These are conditions which need not prevent a woman, in the event of a further pregnancy, from delivering herself by the natural passages, when the scar will be subjected to severe strain and possible rupture.

In the present case a primigravida, aged 24 , with a con. tracted pelvis was submitted to Cæsarean section on March 28th, 1918. The patient was in labour 22 hours and many vaginal examinations were made before the operation. The uterus was opened by the usual anterior median incision and subsequently sutured with three layers of formalin catgut, a layer for the endometrium, a deep buried layer including the whole thickness of the muscle, and a peritoneal layer. The placental site was not noted; a living female child was extracted. A bout the fifth day the patient had a severe rigor, temp. $104^{\circ} \mathrm{F}$. The discharge from the uterus became fotid and the uterus was washed out, when pieces of suture and debris came away. Recovery was protracted.

Second Pregnancy--Readmitted to hospital June 9th, 1920 The patient was in labour six hours before the operation. No vaginal examinations were made. Dr. C. operated as on the first occasion, and delivered a living female child; the patient made a good recovery.

Third Pregnancy.-Readmitted Sept. 21st, 1921. The patient was in labour 18 hours before the operation. No vaginal examinations were made. The only distress complained of being slight tenderness over the abdomen when the nurse was preparing her for the operation.

* Read at a meeting of the Ulster Medical Society.

The Apparatus for Measuring Small Quantities of Fluid.

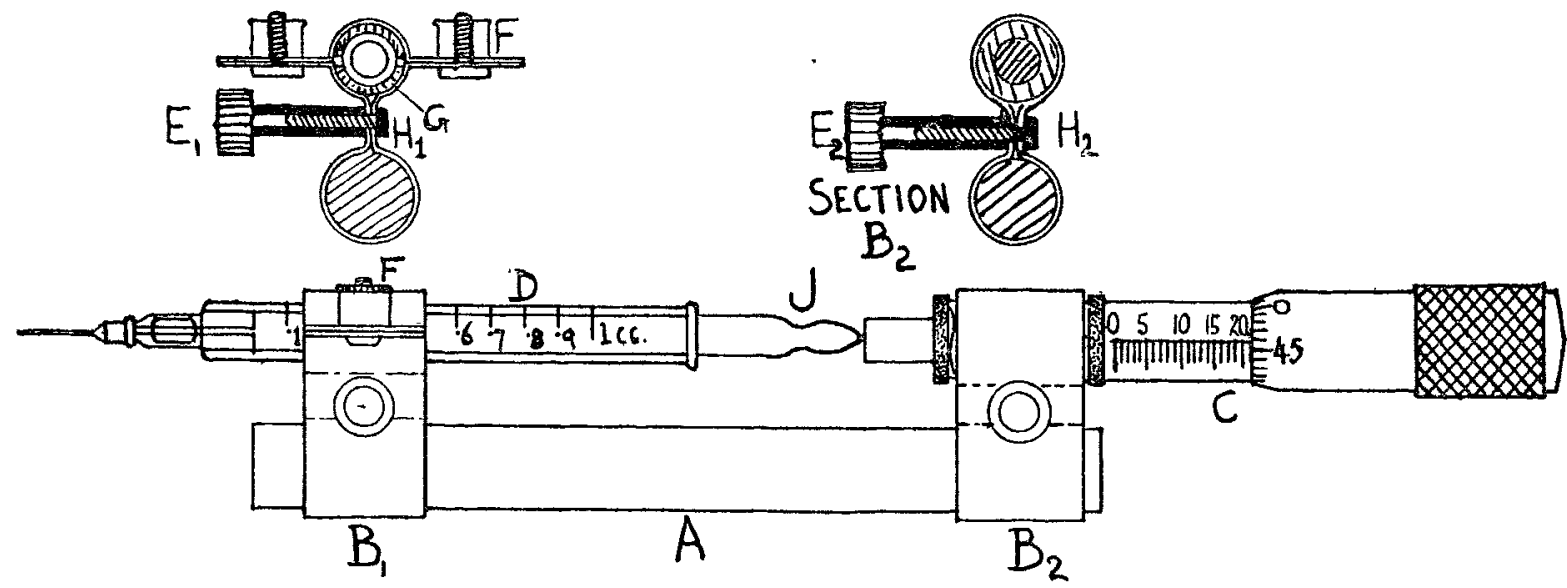

Micrometer syringe made with detachable micrometer head. A, in. steel rod. B1, B2, brass clips (see section above). C, micrometer head, which can be obtained at any tool shop, $25 \mathrm{~mm}$. in 1/100 mm. D, $1 \mathrm{c.cm}$. "tuberculin" syringe. E1, E2, milled heads with screw in shank, for tightening clips ; the male screw, $H$, fits into these and is soldered to the clip. F, electrical binding screws for fixing syringe in clip. G, chamois leather lining. J, head of viston drawn ont to clip. in, electrical binding screws for fixing syringe in clip. $x_{\text {, }}$ chamois leather lining. J, head of piston drawn out to The same result could be obtained by grinding the head of the piston to a flat surface. 
Operation.-The abdomen appeared irregular with a tumour filling the lower half and upper right quadrant. On opening the abdomen I found the dead foetus and placenta free in the peritoneal cavity, and lying just outside a large gaping rent in the anterior wall of the uterus. After removing the foetus and placenta attention was turned to the uterus, which was rigidly contracted and anæmic; a long widelygaping rupture occupied almost the whole length of the anterior wall (Figs. 1 and 2). The rupture looked like clean tear except at its upper end, where it extended laterally to a slight extent. Its edges are thick and smooth, giving the false impression that the rupture occurred through the entire thickness of the uterine wall. Projecting from the thick edge of one side is a ragged leaf of thickened peritoneum. This is in reality the stretched scar, which.ruptured not along its middle but along the junction with the other thick edge At the lower end of the rupture there is a bridge of thickened peritoneum passing between the two edges of the ununited muscle (Fig. 2). The uterus was removed by sub-total hysterectomy. The patient made a good recovery.

\section{Clinical Points.}

There are two varieties of ruptured uterus. Cases with acute symptoms, sudden collapse, signs of intraperitoneal hæmorrhage, cessation of labour pains, and the distinct feeling on abdominal palpation of the fotus and the contracted uterus. These symptoms are met with when the rupture has occurred through the whole thickness of the uterine wall.

Cases with absence of or very slight symptoms. In these cases the rupture occurs in a membranous and avascular scar quietly and gradually during the later stages of pregnancy or early in labour. The membranous scar yields at one point, a small bag of membranes bulges through, and labour continues through a gradually yielding scar until the ovum is born into the peritoneal cavity. The severity of the symptoms will depend upon the position of the placenta. If the placenta is implanted over the scar even a small perforation may be accompanied by a severe intraperitoneal hæmorrhage. If the placenta is well away from the scar it separates and is expelled into the peritoneal cavity with very little more hæmorrhage than occurs after a normal labour.

Time of Rupture.-In the reported cases collected by Eardley Holland rupture occurred almost as often during pregnancy as during labour, the proportion being three to four, the frequency being 4 per cent.

Causes of Rupture.-Perfect healing of the uterine incision may result in complete muscular regeneration leaving no trace of scar tissue except on the peritoneal

Fig. 2.

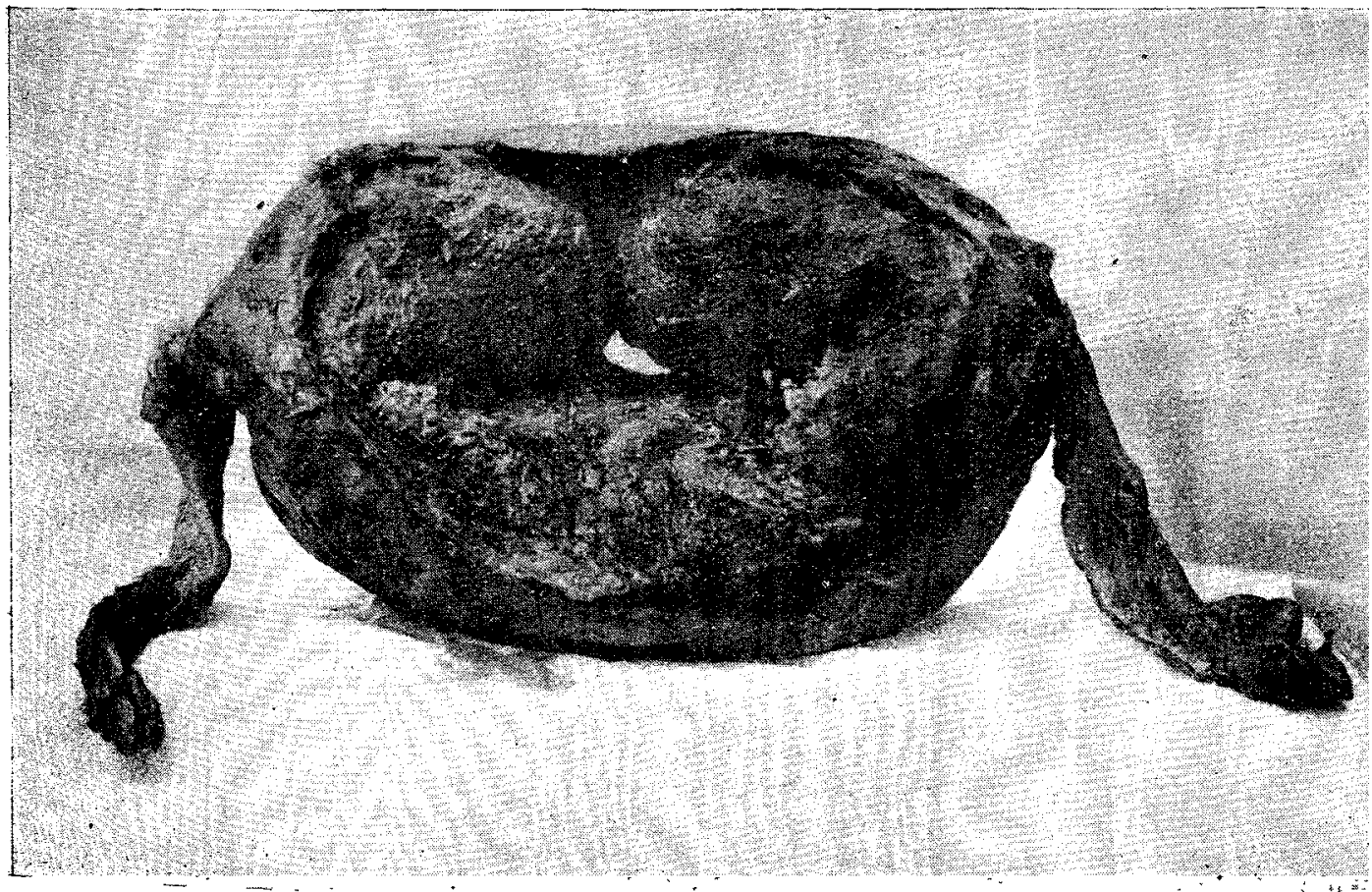

Ruptured uterus, looking from above downwards,
FIG. 1.

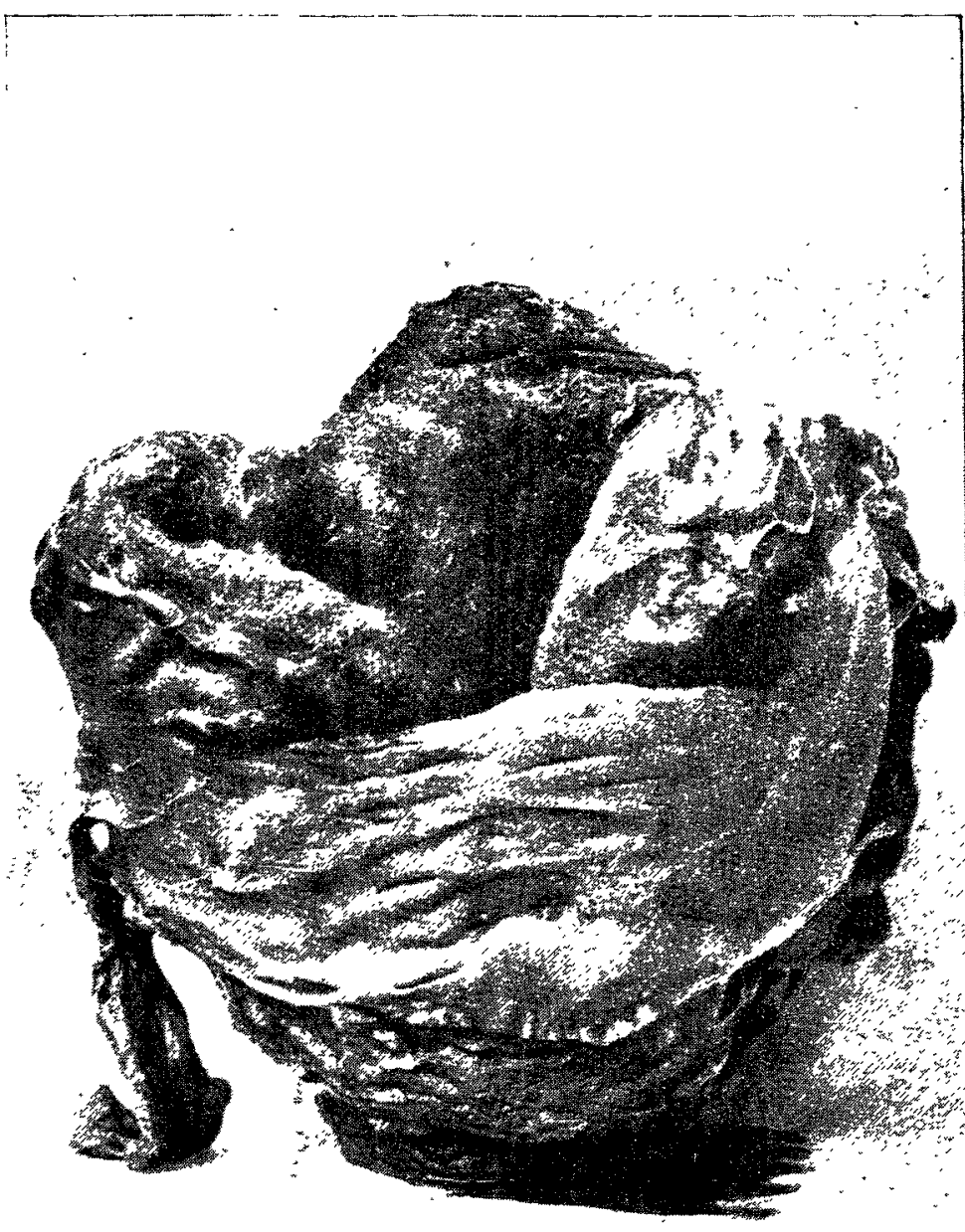

Ruptured uterus, anterior view.

surface. The difficulty is to secure complete asepsis in the uterine wound because of the double danger of infection from the abdominal wound and from below, especially in cases previously examined and interfered with from the vagina. As in all wounds, sepsis is the most important cause of rupture, causing as it does imperfect healing of the uterine incision. Another factor is that the ligatures have to be employed not only as coaptors but also as hæmostatic agents in an organ which subsequent to operation is not only in a state of unrest, but is also in a state of autolysis. This causes a yielding of the sutures employed to close the incision and the muscular surfaces will retract and become widely separated. The peritoneum, on the contrary, holds firm and in course of time becomes covered by a layer of endometrium, which in a subsequent pregnancy is converted into decidua. Further thinning of this peritoneal-decidual scar is the natural sequence of the progressive distension of the uterus during pregnancy, the scar being gradually converted into 
a widely stretched area. These peritoneal-decidual scars are the ones most likely to rupture during pregnancy or labour from a rise in intra-uterine pressure.

\section{How Can Conditions be Improved?}

These conditions can be improved firstly by practising such measures as will prevent sepsis. The pelvis should be carefully examined some time before the commencement of labour, and if pelvic contraction or other deformity is found, appropriate treatment should be given. At the time of operation delivery of the placenta should be per vaginam to prevent the cervical portion of the membranes causing contamination. The uterus should be swabbed with an antiseptic lotion and then douched from above through the uterine incision, allowing the lotion to run out freely through the dilated cervix below. Careful uterine suturing during retraction, not during contraction, should be carried out. The material used for the sutures does not matter, the chief point is that the sutures should start well outside the edge of the incision, so as to include a good thickness of the uterine wall, except the decidua. After this layer is tied the peritoneal edges are accurately united. An alternative operation is the lower segment or cervical method which has lately been revived with a greatly improved technique; its chief exponent in this country is Prof. Munro Kerr. ${ }^{1}$

\section{TESTS OF RENAT EFFICIENCY.*}

\section{BY FRA N K KID, M.A., M.CH. CAMB.,} F.R.C.S. ENG.,

IATF SURGEON TO THE IONDON HOSPITAT; MEMBER OF THE INTERNATIONAL SOCIETY OF UROLOGY ; MEMBRE DE L'ASSOCIATION FRANÇAISE D'UROLOGIE.

Closely following the physiologists in the "seventies" and "eighties" of last century, the urinary surgeons searched for clinical tests of renal efficiency; they had urgent need for such tests, not only when considering nephrectomy and prostatectomy, but also when planning many other operations on the kidney or bladder. During the later years of last century, and in the first decade of the present century, Albarran and Kapsammer and their pupils were doing pioneer work in applying physiological knowledge to clinical purposes in order to find practical tests for estimating the power of the kidneys. These tests were, I believe, first introduced to English medicine in a book by Mr. Thomson Walker, "The Renal Function in Urinary Surgery" (1908) ; and in my book "Urinary Surgery" (1910) I passed in review the special renal tests then in use, and throughout the book pointed out how they should be employed in urinary surgery. Though some of us have employed these tests as routine measures for many years, the English profession as a whole has only lately wakened up to their importance-largely owing, I believe, to the prevalence of "trench nephritis" during the war.

Some of those who have taken up these tests in the last few years with enthusiasm have, I think, been led into confusion, because they have applied certain tests, fashionable at the moment, and have recorded them in great detail in their case records without much attempt to interpret the results; but it is of little use to apply tests unless you know how to interpret the results obtained, and also know on which to rely of all the numerous tests that have been placed on the theoretical market. Others have denied the benefit of prostatectomy to patients with poor functional renal tests, unaware that a two-stage operation can steer the way safely past kidneys depressed by back pressure.

* THE LANCET, 1920 , i., 1065 .
* paper based on a contribution to a discussion of Tests of Renal Function, held at the Section of Urology of the Troval Society of Mtedicine.
The Surgeon's Problems.

As regards tests of renal efficiency, the surgeon is particularly interested in two problems. (1) In considering prostatectomy to know if the kidneys are so. far destroyed by back pressure as to necessitate the carrying out of the operation in two stages. (2) In considering nephrectomy of one diseased kidney, to know if another kidney is present and fit to carry on if left by itself. In answering these questions renal function tests cannot stand by themselves; they must always be coördinated with all other clinical evidence available in any particular case.

A proof that these tests are of great value is that since their universal adoption by urinary surgeons the results of nephrectomy and prostatectomy have improved in a remarkable manner. The percentage mortality of nephrectomy has fallen from 40 per cent. in the latter end of last century to less than 2 per cent., and that of prostatectomy from 30 per cent. to less than 5 per cent. at the present day.

Classification of "Renal Efficiency" Tests.

Tests can be time tests pure and simple, or more elaborate quantitative tests. Time tests are found to be more reliable in practice than quantitative tests, and they are more easily carried out by the clinician.

\section{A. Excretion Tests.}

Applied to bodies excreted in the urine-time and quantitative tests.

1. No Artificial Stimulation.-Average daily quantity of water, colour, specific gravity, urea, chlorides, phosphates, albumin. Cryoscopy (Dreser 1892, Koranyi 1897) and index of refraction-measure of the molecular content of the urine. Measurement of electrical resistance (ionic content) after the method of Kohlrausch (Richter 1903, Dawson 'Turner 1906-07, Leyton 1912). Diastase (Wohlgemuth 1908-11), lactose, benzoic acid (1879).

2. Artificial Stimulation.-Time tests and quantitative tests applied by injecting certain substances into the tissues and noting their appearance in the urine. Dye-stuffs : Indigo-carmine (Heidenhain 1874, Voelcker and Joseph 1903); phenolsulphonephthalein (Rowntree and Geraghty 1910-12) ; methyleneblue (Casper 1892, obsolete because partially excreted as a colourless chromagen) ; fuchsin ; rosanilin, \&c. Drugs : Phloridzin-sugar (von Mehring 1882, Zuntz 1888); urea (Albarran 1905, McCaskey 1913-14, Pirondini 1914); iodides; salicylates, \&c. Water: Experimental polyuria (Albarran 1897-1903, giving excellent results but impracticable and unwise as ureteric catheters have to be left in situ for some hours). Alkalies and acids: Bicarbonate tolerancetest (Sellard).

\section{B. Retention Tests.}

Applied to excretory products retained in the blood, quantitative tests only: Urea and total nitrogen of blood; acidosis and artificial acidosis; chlorides (retention in many cedema cases and possible cause of œdema and high blood pressure in parenchymatous nephritis ; indican; toxicity of urine (Bouchard); cryoscopy (Koranyi 1897)-molecular content; electrical resistance-ionic content.

\section{Correlation Tests or Homorenal Indices.}

Comparisons made between the amount of substances in the blood and whole urine, or in the blood and the urines separated from each kidney: Urea (Ambard's constant); ions (electrical resistance method); molecules (cryoscopy); Wright's tests (hæmolysis).

The surgeon has a wide list from which to choose, and he needs a guide as to which tests are practical and which are not. My own experience leads me to advise that in the case of ureteric catheterisation he should rely chiefly on three tests-namely, a good dye test, indigo (which I prefer) or the phthalein test a good retention test-namely, the blood urea; and a good and simple correlation test-namely, the hæmorenal index as applied by the Kohlrausch electrical resistance method, which I have found of great use and easy to employ for oneself. In prostat- 